\title{
Questões de gênero: incontáveis caminhos no universo da literatura
}

\author{
Questões de gênero: literatura e \\ gênero, coletânea de estudos de \\ literatura brasileira.
}

DALCASTAGNÈ, Regina (Ed.).

Brasília: Gráfica Qualidade, № 32, 2008. 219 p. Capa e projeto gráfico de Anderson Moreira Lima.

Trata-se de uma publicação semestral do Grupo de Estudos em Literatura Brasileira Contemporânea da Universidade de Brasília, com o apoio do Departamento de Teoria Literária e Literaturas da UnB. O foco principal da revista é fomentar debates críticos sobre a literatura contemporânea produzida no Brasil, em suas variadas manifestações teóricas e metodológicas, estendendo-se a outras literaturas, em especial da América Latina. A revista, além de sua área temática, aceita artigos sobre perspectiva comparada, sem restrição ou vertente teórico-metodológica. Possui três seções fixas distintas: uma de dossiês a respeito de um tema relevante da área, uma de artigos e ensaios diversos e uma de resenhas.

O presente número traz um dossiê a respeito de Literatura e Gênero, com dez ensaios, seguido de quatro artigos e duas resenhas. A maioria dos autores é formada de professores doutores de diversas universidades do Brasil e do exterior. Os demais são doutorandos e mestres.

Em "Narrativas cosmopolitas: a escritora contemporânea na aldeia global", Sandra Regina Goulart Almeida discute como os pressupostos teóricos da contemporaneidade podem ser pensados em termos de estudos de gênero. A autora divide seu texto em duas partes: 
"Narrativas cosmopolitas" e "Uma escritora contemporânea na aldeia global". A primeira parte do estudo aborda questões problemáticas em relação à mulher no novo contexto sociocultural. Na segunda parte a autora discute as visões de uma escritora contemporânea, tomando como base o conto da pernambucana Marilene Felinto, "Muslim: Woman", cuja narrativa explora o encontro de duas mulheres, simbolicamente, em um aeroporto africano.

Simone Pereira Schmidt, em "De volta para casa ou o caminho sem volta em duas narrativas do Brasil", discute a representação do corpo feminino subalterno em dois romances brasileiros: As mulheres de Tjucopapo (1982), de Marilene Felinto, e Ponciá Vicêncio (2003), de Conceição Evaristo. A narrativa enfoca o corpo como lócus em que se desdobram as tensões resultantes das relações desiguais de gênero, raça e classe no Brasil; corpo colonizado e verdadeiro campo de batalha. Aborda, também, os deslocamentos efetuados pelas personagens femininas nos dois romances como percursos formadores de sua personalidade. $O$ marco inicial da formação das duas protagonistas, Rísia e Ponciá, é a estrada: "As personagens das narrativas em questão desejam falar de sua experiência, [...] tomam a estrada, não se fixam, vão, voltam, buscam. A questão identitária que está posta nesta busca é vital para cada uma delas" (p. 26).

Em "Deslocar-se para recolocar-se: os amores entre mulheres nas recentes narrativas brasileiras de autoria feminina", Virgínia Maria Vasconcelos Leal discute a representação, na literatura brasileira contemporânea, de um grupo social em que se cruzam duas categorias identitárias consideradas marginalizadas: o gênero e a homossexualidade.

No caso de "Gêneros indefinidos e corpos inadequados revelam ideal feminino inatingível, em Deixei ele lá e vim, de Elvira Vigna", Adelaide Calhman de Miranda analisa a representação dos corpos na construção da identidade feminina no romance policial citado. O fracasso, a exclusão social e até a morte são vistos como consequência da falta de adequação física das personagens ao modelo ideal de corpo. A imposição do padrão ideal é revelada como violência simbólica, que resulta em doenças, disfunções e outros tipos de sofrimento físico e psicológico. A autora divide este dossiê em três partes: "O corpo é submetido a vários tipos de violência", "O sexo indefinido aponta a arbitrariedade da construção social dos gêneros" e "A história falsa de Shirley Marlone ilustra a arbitrariedade do padrão cultural da mulher".
Maria da Glória de Castro, ao analisar "O interdito no ideal de nação: a lesbiana existe para a literatura brasileira?", pensa no porquê do silenciamento e da marginalização de produções literárias que transitam pela temática da homoafetividade feminina, a partir da produção de Cassandra Rios, autora pioneira na construção de uma literatura gendrada à sexualidade lesbiana. O texto de Maria da Glória questiona essa temática em relação ao desprestígio e ao silenciamento sofridos pela escrita de autoria feminina.

No texto "Nas tramas da memória: a cronista e militante Eneida de Moraes", Eunice Ferreira dos Santos mostra, através da articulação de sua obra, a militância político-partidária. Examinou textos extraídos dos livros que compõem a trilogia memorialística de Eneida: Cão da madrugada (1954), Aruanda (1957) e Banho de cheiro (1962). Para o enfoque crítico, respaldou-se em bibliografias documentais localizadas nos arquivos da Delegacia da Ordem Política e Social de São Paulo e do Superior Tribunal Militar (STM). A autora dividiu seu texto em "A escrita de Eneida em algum lugar da história políticoliterária brasileira" e "A cronista e a militante: o ideário comunista revisitado pela memória", este último subdividido em "Cão da madrugada" e "Aruanda e Banho de cheiro".

Em "A escrita de autoria feminina no Paraná: Greta Benitez e a alquimia das letras", Níncia Cecília Ribas Borges Teixeira tem como meta contribuir para a discussão sobre a representação do papel da mulher na sociedade contemporânea, a partir do viés literário, além de proporcionar visibilidade acadêmica à escritora paranaense Greta Benitez. Examina a relação entre literatura e a presença das mulheres nas práticas sociais, numa sociedade que cria a imagem negativa do feminino e a projeta como outro. Níncia constrói seu texto dividindoo em subtítulos: "Retratos da escrita de autoria feminina: cenas paranaenses", "Greta Benitez: o exercício da liberdade total" e "Conclusão".

Em "Gênero e 'raça' na literatura brasileira", Florentina Souza discute as relações entre gêneros e raça baseadas em estudos realizados sobre representações de mulheres negras, revendo tópicos dos estudos contemporâneos focalizados na literatura brasileira. Aponta diferentes opiniões de escritores que trabalharam a forte relação entre raça, gênero e sexualidade.

"Fios comuns", estudo baseado em oposições binárias, relativismos ou universalismos, noções outras do eu e do outro, do humano e do não humano, do meio ambiente e das técnicas do corpo, no qual Norma Telles enfoca, 
também, divergentes leituras sem se misturarem por serem afirmadas na diferença e na diversidade, na fluidez e na flexibilidade do fio de Ariadne. A autora destaca a interligação do humano e do literário e faz considerações sobre a literatura escrita por mulheres.

No texto "Centro e margens: notas sobre a historiografia literária", Rita Terezinha Schmidt tece considerações sobre teoria e seus efeitos no campo literário e o ressurgimento do interesse sobre a história da literatura, problematizando a narrativa das histórias de literatura brasileira com base em pesquisas sobre o século XIX. Enfoca, também, a recuperação de dois romances de autoria feminina: Memórias de Marta (1888), de Júlia Lopes de Almeida, e Úrsula (1859), de Maria Firmina dos Reis, segundo Schmidt, "para ilustrar questões de representação e relações diferenciais em relação a obras canônicas de seu tempo" (p. 134).

Na segunda seção - artigos e ensaios diversos -, a Revista de Estudos de Literatura Brasileira Contemporânea apresenta quatro ensaios.

"Poema e bala perdida", de lumna Maria Simon, que analisa o poema "Sítio", de Claudia Roquette-Pinto, registrando a conversão da opacidade, do lacunar e da indeterminação da experiência da violência urbana e da miséria emocional dos protegidos, isto é, da contaminação do mundo privado pelo fato externo.

"Quando Helena Kolody cruzou a fronteira", de Luisa Cristina dos Santos Fontes, que analisa, através de relatos de Helena, como a percepção do sentimento de exílio acompanha a personagem, que se assume como portadora de vozes construídas deste "entrelugar". O poema, como operador de memória, trabalha na tentativa de entrecruzar memória coletiva e histórica.

"Longe do paraíso: Jazz, de Toni Morrison, e Ponciá Vicêncio, de Conceição Evaristo", de Ângela Maria Dias, que propõe a interpretação das obras das escritoras citadas, explorando as correspondências entre memória e criação de ambas. Sua investigação pretende interrogar o papel do cânone na busca da reconstrução de uma identidade histórica e ficcional, enfocando especificidades características dos cânones afroamericano e afro-brasileiro, delineando a ética do engajamento político de Morrison e Evaristo, seja ele de raça e/ou de classe e/ou de gênero.

E "De Pequod a Satolep: identidades em jogo na obra de Vitor Ramil", de Luciana Wrege Rassier, que visa à análise dos romances do escritor gaúcho Vitor Ramil Pequod (1995) e Satolep (2008), no intuito de identificar de que modo o autor trata questões como identidade, alteridade, criação artística e intertextualidade, que refletem as principais ideias desenvolvidas em seu ensaio "A estética do frio" (1992 e 2004). Luciana divide esse trabalho em quatro subtítulos: "Identidade em construção: a estética do frio", "Pequod: (des)construção através da linguagem", "(Re)construção a partir das ruínas: Satolep" e "De Pequod a Satolep, diário de viagem".

Na terceira seção - resenhas -, a revista apresenta dois cuidadosos trabalhos: "Elódia Xavier - Que corpo é esse? O corpo no imaginário feminino" (2007), de Maria do Rosário Alves Pereira, e "T.V. Dijk (Org.) - Racismo e discurso na América Latina" (2008), de João Vianney Cavalcanti Nuto.

No primeiro, Maria do Rosário brinda seu leitor com detalhado comentário da obra de Elódia Xavier, abordando desde referências à autora, prefácio da obra, de Antonio Carlos Secchin, às dez categorias que a escritora estabelece sobre o corpo, fio condutor de seu livro. Maria do Rosário fala de cada uma das categorias, não se esquecendo de citar as autoras e obras consultadas, de forma clara e objetiva, incitando o leitor à procura imediata do livro.

No segundo trabalho, Nuto privilegia a Linguística contemporânea e os estudos do discurso como reveladores de possibilidades para outros tipos de estudo, inclusive sobre o racismo. Ressalta que o livro apresenta reflexões e conclusões sobre o discurso em oito países, revelando o caráter mais insidioso da ideologia racista em cada um deles e a contribuição interdisciplinar de linguistas, sociólogos, antropólogos e outros cientistas sociais para se pensar a transformação do mundo num espaço menos preconceituoso.

Os colaboradores desta conceituada revista recorreram à diversificada bibliografia. Além de utilizarem as obras estudadas nos diversos trabalhos, buscaram embasamento teórico em escritores do mais alto gabarito, como Mikhail Bakhtin, Stuart Hall, Gilberto Freyre, Marilena Chauí, Pierre Bourdieu, Michel Foucault, Simone de Beauvoir, Jacques Derrida, Elaine Showalter, Virginia Woolf, Constância Lima Duarte, Graciliano Ramos, Hélène Cixous, Umberto Eco, Teresa de Lauretis, Levi-Strauss, Peggy Sharpe, Roland Barthes, Walter Benjamin, Gilles Deleuze e muitos outros.

Em síntese, os autores cumpriram com brilhantismo seu papel incentivador, objetivando a ampliação dos conhecimentos dos seus leitores através de novos estudos.

Maria Inês de Moraes Marreco Pontifícia Universidade Católica de Minas Gerais 